\title{
Egg Allergy in infancy
}

\author{
Shrestha $\mathrm{R}^{1}$, Shrestha $\mathrm{D}^{2}$, Poudyal $\mathrm{R}^{2}$, Mishra $\mathrm{N}^{2}$
}

${ }^{1}$ Lecturer, Department of Dermatology

${ }^{2}$ Lecturer, Department of Paediatrics

KIST Medical College

Imadol, Lalitpur, Nepal.

\section{Correspondence}

Dr. Rima Shrestha, Dr.Devendra Shrestha

KIST Medical College, Imadol, Lalitpur, Nepal.

e-mail address: rimashrestha00@yahoo. com, devendra.shrestha@gmail.com

\begin{abstract}
Egg allergies are one of the most common allergies of childhood and the reactions may vary from mild to severe. A family history of egg allergy or atopy is a risk factor for egg allergy. Most food-induced allergic reactions occur on first known oral exposure, especially in the case of eggs and peanuts. We report a case of nine months old infant who developed egg allery (contact dermatitis) after contact with egg white, with a positive family history of atopy and egg allergy.
\end{abstract}

\section{Keywords}

Egg allergy, contact dermatitis, infancy.

\section{Introduction}

Food allergy is defined as an adverse reaction due to abnormal immune response resulting from the ingestion of food or additive. ${ }^{1}$

Food allergy occurs in atopic individuals who produce $\mathrm{IgE}$ antibodies to food proteins. Foods most commonly involved are egg, milk, peanut, sesame, fish, seafood, wheat and soy.

Egg white allergy occurs when the immune system of the body mistakes the protein for an allergen and reacts against it. The allergic reaction is easily triggered in those people with egg allergy when they come in contact with the egg either through touching, smelling or eating. Reactions usually occur immediately after food ingestion ${ }^{2,3}$ and may manifest as an acute rash around the mouth with redness and swelling of the face. More severe reactions progress to urticaria, angioedema, breathing difficulty, vomitting, and/or anaphylactic shock, sometimes resulting in death. ${ }^{4,5}$

Some people are allergic to the whole egg, while others are allergic to either the yolk or egg white. Egg white allergy in children is the most common $t$ and the reaction may vary from mild to severe. The severity of egg allergy may occur immediately and can even be life-threatening.

\section{Case Report}

Nine months old male was brought with complaints of erythematous itchy papular rash over perioral area along with swelling of the lips within half an- hour following an attempt of feeding eggwhite over the area of contact of the egg. Fortunately, parents gave the history that the infant did not ingest the egg. There was no histry of vomiting, loose stools, breathlessness, wheezing and skin lesions elsewhere in the body. And no histry of any new food ingestion prior to reaction. He was delivered by elective Lower Segment Caeserean Section and had developed neonatal sepsis with pneumonia requiring NICU admission and ventilatory support.

On dermatological examination; erythematous pruritic, ill-defined confluent urticarial papules and plaques on the perioral area without angioedema were noted. (Figure 1 and Figure 2) 
On past history at 6 months of age, he had developed erythematous maculo-papular rash over face and trunk following ingestion of egg. The skin lesions subsided after few hours and he was treated with oral anti-histamine. Similar type of skin lesions again re-occured after feeding of egg at 7 months of age. During both episodes there was no histry of loose stool, vomiting, breathelessness.

However, there were no symptoms after ingestion of chicken since 6 months of age.

There was positive family histry of allergy with egg in maternal uncle and aunt in whom unlike this baby, had predominant abdominal symptoms like cramps and dyspepsia.

His total leukocyte count was $7080 / \mathrm{mm}^{3}$, Neutrophil $32 \%$, Lymphocyte 60\%, Monocyte 2\%, Eosinophil 6\%.
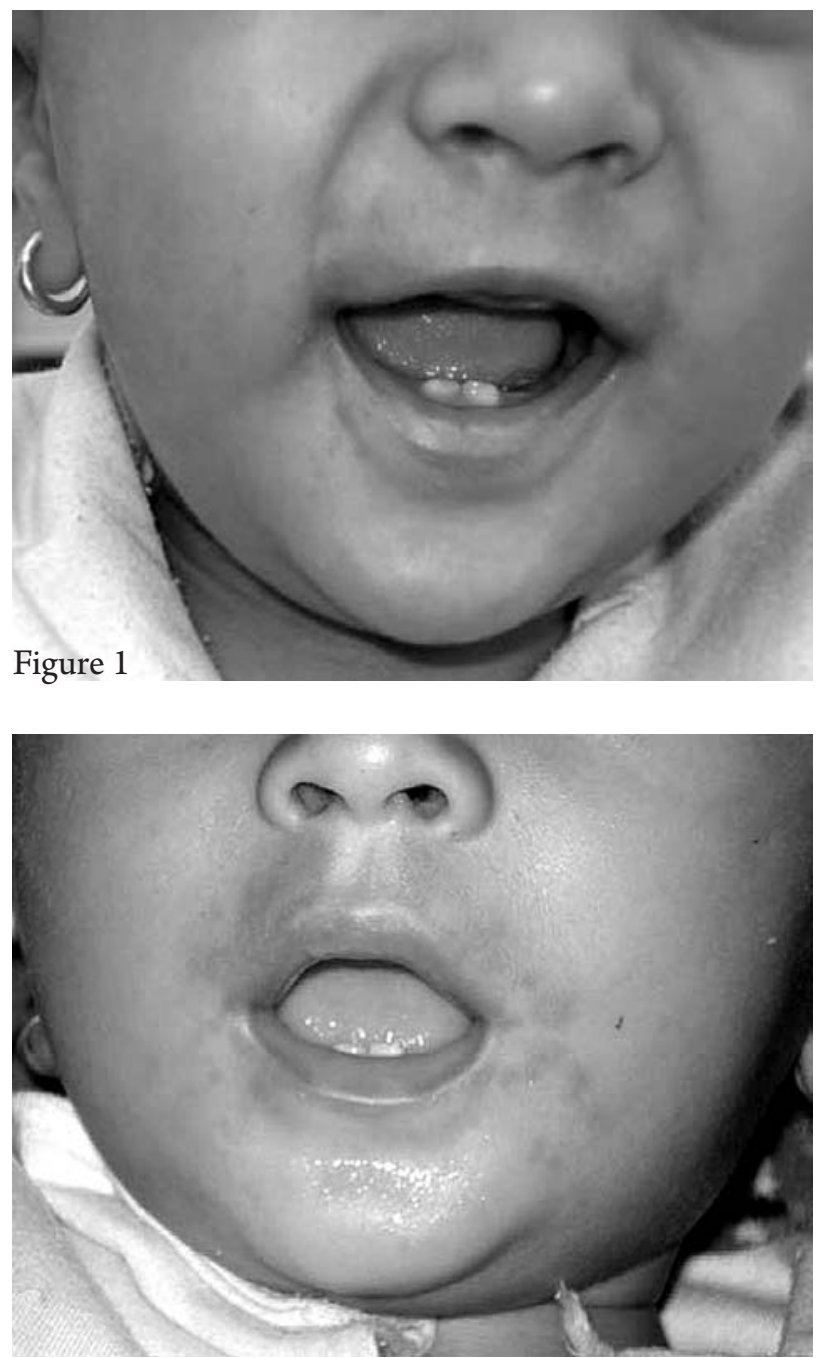

Figure 2

The parents were councelled and adviced to eliminate egg and egg containing food from the diet, and come to the hospital if he develops any adverse reaction.

\section{Comment}

We are going to review his egg allergy in the subsequent months. Recent literature reported two-third children may eventually outgrow the condition by school age.

\section{Discussion}

Population-based studies show that the prevalence of allergy to egg whites among children is between 1.5 and $3.2 \% .^{6-8}$

Egg white allergens include ovalbumin, ovomucoid, ovomucin, ovotransferrin and lysozyme ${ }^{9}$. There are also multiple allergenic proteins in egg yolk, with the most common being alpha-livitin. The reduction in allergenicity by heat or gastric digestion provides an explanation for those children who react to uncooked but not cooked egg, ${ }^{10,11}$ and for subjects who react to egg after cutaneous contact but not after ingestion. ${ }^{12}$ It is also observed that children who are allergic to hen's eggs are not allergic to chicken ${ }^{13}$.

Children are frequently found to be sensitised without having a previous history of egg ingestion ${ }^{12}$.

The clinical onset is usually in the first year of life, often with the first introduction of a food, and is strongly associated with atopic eczema.

Multiple foods are frequently involved in children but, from around 5 years, allergy to only one or two foods is the normal ${ }^{3}$. Most children outgrow milk, egg, soy and wheat allergies before they reach school age.

Egg allergy generally has a good prognosis. Despite recent advances in oral immunotherapy trials, the treatment of egg allergy currently relies on avoidance of egg-containing foods until tolerance has developed. It remains unclear whether the ongoing low-dose exposure to egg proteins in cooked foods improves the natural history of egg allergy ${ }^{14}$. Families of children with food allergies need clear guidance on how to prevent accidental exposure to allergens, recognize symptoms of anaphylaxis, and respond appropriately. Since most children will outgrow their allergies to milk, egg, soy and wheat, follow-up testing will help monitor the development of tolerance and indicate when these foods can be safely reintroduced into the child's diet.

Egg avoidance advice is the cornerstone of management. Egg allergy often resolves and re-introduction can be achieved at home if reactions have been mild and there is no asthma. Patients with a history of severe reactions or asthma should have reintroduction guided by a specialist. All children with egg allergy should receive measles, mumps and rubella (MMR) vaccination. Influenza 
and yellow fever vaccines should only be considered in egg-allergic patients under the guidance of an allergy specialist. This guideline was prepared by the Standards of Care Committee (SOCC) of the British Society for Allergy and Clinical Immunology (BSACI $)^{15}$.

\section{Conclusion}

As the prevalence of food allergies rises worldwide, it is important that physicians are able to accurately diagnose and manage this problem at the primary level. Patient's history is the most significant aspect of the evaluation; this is followed by physical examination, which often reveals signs of allergic reaction. We must also continue to educate all those involved in the care of the child. Moreover, prepare them to handle an emergency -such as anaphylactic shock. As novel and effective methods emerge for modulating the immune system, we can say that the future is promising for those suffering from food allergies.

\section{References}

1. Zuhre K, Esin KOC. An interesting case of cow milk protein allergy in neonatal period. Gazi Med Journal 2001;12:203-205.

2. Scurlock AM, Lee AL, Burks AW. Food allergy in children. Immunol Allergy Clin N Am 2005; 25:369-88.

3. Allen JA, Hill DJ, Heine RG. Food allergy in childhood. Med J Aust 2006; 185:394-400.

4. Liew WK, Williamson E, Tang MLK. Anaphylaxis fatalities and admissions in Australia.J Allergy Clin Immunol 2009; 123:434-42.

5. Poulos LM, Waters AM, Correll PK, et. al. Trends in hospitalizations for anaphylaxis, angioedema, and urticaria in Australia, 1993-1994 to 2004-2005. J Allergy Clin Immunol 2007;120:878-84.

6. Fleisher DM. The natural history of peanut and tree nut allergy. Curr Allergy Asthma Rep 2007; 7:175-81.

7. Sicherer SH, Sampson HA. Peanut allergy: Emerging concepts and approaches for an apparent epidemic. J Allergy Clin Immunol 2007;120:491-503.

8. Poulsen LK, Hansen TK, Norgaard A, Vestergaard H, Stahl Skov P,Bindslev-Jensen C. Allergens from fi sh and egg. Allergy 2001;56 Suppl 67:39-42.

9. Romeira AM, Pires G, Gaspar A, Arede C, Morais-Almeida M, Rosado-Pinto J. Egg allergy - to be or not to be boiled. Allergy 2003;58:533-4.
10. Lemon-Mule H, Sampson HA, Sicherer SH, Shreffl er WG, Noone S, Nowak Wegrzyn A. Immunologic changes in children with egg allergy ingesting extensively heated egg. J Allergy Clin Immunol 2008;122:977-83.

11. Yamada K, Urisu A, Haga Y, Matsuoka H, Komada H, Torii S. A case retaining contact urticaria against egg white after gaining tolerance to ingestion. Acta Paediatr Jpn 1997;39:69-73.

12. Monti G, Muratore MC, Peltran A, Bonfante G, Silvestro L, Oggero R,et al. High incidence of adverse reactions to egg challenge on first known exposure in young atopic dermatitis children: predictive value of skin prick test and radioallergosorbent test to egg proteins. Clin Ex Allergy2002;32:1515-9.

13. Kemp A,Chiang WN, Gerez I, Goh A et al. Childhood food allergy: A Singaporean perspective. Ann Acad Med Singapore 2010;39:404-11

14. Tey, Dean; Heine, ralf G. Egg allergy in childhood. An update. current opinion in allergy and clinical immunology2009;9:244-50

15. T. Clark, I. Skypala, S. C. Leech, P. W. Ewan, P. Dugué, N. Brathwaite, P. A. J. Huber and S. M. Nasser, Clinical \& Experimental Allergy, 2010 (40) 1116-1129. 